\title{
Atmospheric circulation patterns associated with extreme cold winters in the UK
}

Article

Accepted Version

PDF of accepted version of article

Burgess, M. and Klingaman, N. P. (2015) Atmospheric circulation patterns associated with extreme cold winters in the UK. Weather, 70 (7). pp. 211-217. ISSN 1477-8696 doi: https://doi.org/10.1002/wea.2476 Available at https://centaur.reading.ac.uk/38619/

It is advisable to refer to the publisher's version if you intend to cite from the work. See Guidance on citing.

To link to this article DOI: http://dx.doi.org/10.1002/wea.2476

Publisher: Wiley

All outputs in CentAUR are protected by Intellectual Property Rights law, including copyright law. Copyright and IPR is retained by the creators or other copyright holders. Terms and conditions for use of this material are defined in the End User Agreement.

$\underline{\text { www.reading.ac.uk/centaur }}$ 
Central Archive at the University of Reading

Reading's research outputs online 


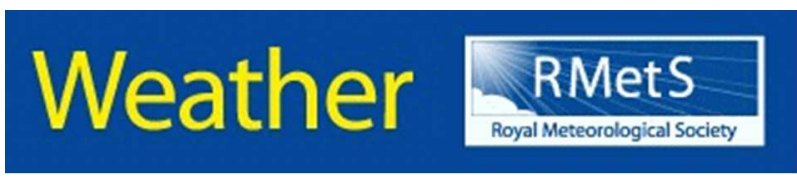

\section{Atmospheric Circulation Patterns Associated with Extreme Cold Winters in the UK. Madlen Burgess and Nicholas P. Klingaman}

\begin{tabular}{|r|l|}
\hline Journal: & Weather \\
\hline Manuscript ID: & WEA-14-0017.R3 \\
\hline Watey - Manuscript type: & Research Article \\
\hline Complete List of Authors: & $\begin{array}{l}\text { Burgess, Madlen; Met Office, Forecasting Sevice and Delivery } \\
\text { Klingaman, Nicholas; University of Reading, National Centre for } \\
\text { Atmospheric Science and Department of Meteorology }\end{array}$ \\
\hline Keywords: & $\begin{array}{l}\text { UK Extreme Winters, Twentieth Century Reanalysis dataset, South } \\
\text { Westerly Winds }\end{array}$ \\
\hline \multicolumn{2}{|c}{} \\
\hline
\end{tabular}


Atmospheric Circulation Patterns Associated with Extreme Cold Winters in the UK.

\section{Madlen Burgess and Nicholas P. Klingaman}

4

\section{Introduction}

Extremely cold winters have been observed in the UK since records began, but the exceptional temperatures during the winters of 2009/10 and 2010/11 greatly increased interest in this topic. With a mean temperature of $-0.7^{\circ} \mathrm{C}$, December 2010 was the second coldest December in the Central England Temperature record (CET; Parker et al., 1992) which dates to 1659 , rivalling only December $1890\left(-0.8{ }^{\circ} \mathrm{C}\right)$. Previous research into the causes of such cold events have found associations with the North Atlantic Oscillation (NAO), Arctic Oscillation (AO), the East Atlantic Pattern (EA), the El Niño-Southern Oscillation (ENSO), blocking events and solar activity as discussed below. Many of these studies have been limited to the past 60-70 years due to a lack of four-dimensional reconstructions of atmospheric conditions (i.e. reanalysis data). This study uses the recently available $20^{\text {th }}$ Century Reanalysis (Compo et al., 2011) to provide the first reliable estimates of the state of the atmosphere during some of the coldest winters of the past 140 years, most of which have fallen outside the scope of past studies.

\section{Known causes of UK cold winters}

The NAO is the dominant mode of Northern Hemisphere extra-tropical atmospheric variability, describing oscillations in atmospheric mass between middle and high latitudes. Variability in this large-scale atmospheric circulation directly influences the risk of European seasonal temperature extremes (Scaife et al., 2008). The NAO has a significant influence on the UK winter climate as its strongest variability and thus its greatest impact on the circulation, occurs during winter (George et al, 2004). A negative NAO reduces the meridional pressure gradient across the North Atlantic, due to either high pressure anomalies over Iceland, low pressure anomalies over the Azores or both; this weakens the climatological westerlies across northern Europe, resulting in less moisture and heat transport to the UK. This typically provides colder and drier winters than the positive $\mathrm{NAO}$, when stronger westerlies result in warmer, wetter conditions. The AO is highly correlated with the NAO (Deser, 2000) and thus also influences winter surface air temperature variability (Thompson and Wallace, 2001). A negative AO is associated with a 
1 weak stratospheric polar vortex which allows intrusions of colder air to reach Europe, Asia

2 and North America (Wang and Chen, 2009).

3 The EA is the second leading climate mode in the North Atlantic (Barnston, 1986). The 4 structure of the anomalous pressure patterns are very similar in the EA as in the NAO, 5 except that the anomaly centres are displaced south-eastwards. By altering the location and 6 strength of the Atlantic pressure centres, the EA influences the location of the warm, moist 7 jet over Europe and thus UK temperatures (Moore and Renfrew, 2012).

8 While the ENSO-NAO teleconnection has been rigorously investigated, the ENSO state 9 provides only marginal predictive skill for European winter climate. Ineson and Scaife 10 (2009) found that during El Niño, a quasi-stationary wave formed by the anomalously 11 deeper Aleutian low can propagate into the stratosphere. This increases the probability of 12 sudden stratospheric warmings, which in turn cause downward-propagating pressure 13 anomalies that at the surface result in a negative NAO/AO pattern. Brönnimann (2007) 14 also found that El Niño (La Niña) favours the negative (positive) NAO. However, this is 15 not a straightforward, consistent relationship due to the large inter-event variability in 16 ENSO strength, position and teleconnections. Its influence on winter-mean conditions is 17 particularly difficult to clarify due to the potential reversal of the ENSO-driven sea-level 18 pressure anomalies in the North Atlantic between early and late winter (Moron and 19 Gouirand, 2003).

20 Other patterns of pressure anomalies can lead to extremely cold winters in the UK, such as 21 blocking anti-cyclones. These conditions enhance extreme cold winters further through 22 reducing cloud cover, allowing strong nocturnal cooling.

23 Anomalous sea surface temperatures (SST) in the North Atlantic have been found to 24 modify the intensity and phase of the NAO due to local changes in surface evaporation, 25 precipitation and heating (Rodwell et al., 1999). In fact, Maidens et al. (2013) found that 26 the main mechanism responsible for the extremely cold winter of 2010 was anomalous 27 ocean heat content and associated anomalous North Atlantic SST. Autumn Siberian snow 28 cover (Cohen and Jones, 2011) and Arctic sea ice (Yang and Christensen, 2012) have been 29 shown to lead wintertime NAO variability, offering the possibility for statistical prediction 30 of European winter climate. 
1 Decadal and multi-decadal variations in solar activity have been associated with extreme

2 UK winters (Lockwood et al., 2010) but this is not a factor that is considered in this 3 investigation. Stratospheric variability can also influence the NAO and hence Northern

4 Hemisphere winter climate; the Quasi-Biennial Oscillation is the main driver on 5 interannual temporal scales (e.g., Ebdon, 1975), while stratospheric sudden warmings can

6 drive strong negative NAO phases on scales of weeks to months (e.g., Baldwin and 7 Dunkerton, 2001).

8 A variety of factors and their interactions therefore can influence the frequency and 9 intensity of extreme UK cold winters. This paper attempts to ascertain any large-scale 10 atmospheric circulation patterns that are consistently associated with such extremes. An 11 improved understanding of the causes of extreme cold winters may lead to more accurate 12 forecasts and mitigate the social and economic impacts.

\section{Motivation}

15 Most of the studies discussed above employed reanalysis data to provide global, four16 dimensional descriptions of the atmosphere. "Traditional" reanalyses, such as the 17 European Centre for Medium-range Weather Forecasting 40-year reanalysis (ERA-40), 18 require systematic upper-air observations, limiting their range to the period since World 19 War II. As we show, this period contains very few of the extremely cold winters of the past 20 140 years. Here, we extend the period beyond and increase the sample size of extreme winters above previous studies (e.g., Hirschi and Sinha, 2007; Moore and Renfrew, 2012) by employing the $20^{\text {th }}$ Century Reanalysis (20CR) which extends to 1871 . We explore atmospheric conditions during winters never previously examined with such a comprehensive atmospheric dataset. This allows us to validate the conclusions of past research based on shorter time periods, as well as to investigate any common atmospheric circulation patterns associated with extremely cold winters in the UK.

Created jointly by the National Centers for Environmental Predication (NCEP) and the 30 National Center for Atmospheric Research (NCAR), the 20CR (Compo et al., 2011) 
1 Databank. Boundary conditions are provided by observed monthly sea-surface 2 temperatures (SST) and sea ice from the Hadley Centre HadISST dataset (Rayner et al., 3 2003). To account for uncertainty due to the lack of upper-air data and the relative scarcity 4 of surface-pressure observations early in the reanalysis period, particularly in the Southern 5 Hemisphere, the 20CR consists of 56 ensemble members by employing an Ensemble

6 Kalman Filter data assimilation scheme (e.g., Evensen, 2003). Six-hourly output is 7 available for 1871-2010 at a $2^{\circ}$ spatial resolution. Because the 20CR dataset ended on 31 8 December 2010 at the time of our study, we analyse winters from 1871-72 through 2009910 (139 winters). Except where otherwise noted, this research uses the ensemble-mean, 10 monthly and seasonal-mean 20CR data. SSTs anomalies are computed using HadISST.

12

\section{Method}

The most extreme cold winters in the UK during the 20CR period were identified by computing the detrended monthly and seasonal CET anomalies for December, January and Feburary (DJF) against the long-term mean. The detrended anomalies were then ranked from the most negative. No winter had high ranking (within the top ten) negative anomalies in all three months. We selected the seven winters with the largest negative DJF-mean detrended anomalies (hereafter "extreme winters"; Table 1), which had a mean anomaly of $-2.5^{\circ} \mathrm{C}$. The next (eighth) coldest winter had an anomaly of only $-1.9^{\circ} \mathrm{C}$. All extreme winters had at least one month in DJF which ranked within the top ten monthly anomalies; the winters of 1878, 1894 and 1962 had two such months. (All winters are referred to by the year in December.) We also directly compare December 2010 and December 1890, as the question of the similarity in the atmospheric circulations between these two extremely cold Decembers motivated this study. Six of the seven extreme winters - all except 1962 - are outside the scope of "traditional" reanalyses such as ERA40; they could not be examined without long-period reanalyses such as the $20 \mathrm{CR}$.

To validate 20CR surface temperatures over the UK, a 20CR CET was calculated and compared to observations. Reproducing the triangular area of the observed CET would have used only two 20CR grid points, which is likely below the effective resolution of the numerical model that produced the 20CR (e.g., Frehlich and Sharman, 2008). Instead, we averaged the eight $20 \mathrm{CR}$ grid points representing all UK land. We demonstrate that the 20CR CET reproduces the observed winter-to-winter variability (see Figure 1 below). 
1 For each extreme winter, anomalies in mean sea level pressure (MSLP), SST, winds at 850

$2 \mathrm{hPa}, 500 \mathrm{hPa}$ and $250 \mathrm{hPa}$, vertical velocities at $500 \mathrm{hPa}$ and $700 \mathrm{hPa}$ and specific humidity

3 at $700 \mathrm{hPa}$ and $850 \mathrm{hPa}$ were examined. To reduce the influence of long-term climate 4 change, anomalies were computed from a running 30-year seasonal mean, with the 5 exceptions of DJF 1878 and December 2010, for which the means of the 1871-1900 and 6 1981-2010 respectively, were used.

7 To examine the influence of south-westerly flow on extreme cold winters, a South

8 Westerly Index (SWI) was created based on the $850 \mathrm{hPa}$ wind speed and direction in a

9 region upstream of the $\mathrm{UK}\left(50-55^{\circ} \mathrm{N}, 18-10^{\circ} \mathrm{W}\right)$ :

$10 \quad \mathrm{sWI}=\sqrt{\left(\mathbf{u}^{2}+\mathrm{v}^{2}\right)} \cos \mathbb{I}\left(\Theta-{ }^{\pi} / 4 \mathrm{l}\right)$

11 where $\mathrm{u}$ is the box-averaged zonal wind, $\mathrm{v}$ the box-averaged meridional wind and $\theta$ is the 12 angle of the box-averaged wind (where 0 is due westerly). The SWI was computed from 13 six-hourly winds for all 20CR ensemble members; the "ensemble-mean" SWI is the mean 14 SWI from all 56 members, not the SWI of the ensemble-mean 20CR winds.

\section{Results}

16 The 20CR ensemble mean accurately reproduces the winter-to-winter variability in CET 17 (Figure 1); the correlation of DJF means with the observations is 0.98. However, the 20CR 18 contains a substantial warm bias of $1.8^{\circ} \mathrm{C}$, shown by the displacement of the $20 \mathrm{CR}$ values 19 from the diagonal dashed line in Figure 1. This is likely because the UK is only at most 20 two gridpoints wide at the $2^{\circ} 20 \mathrm{CR}$ resolution; winter land temperatures are likely biased 21 warm because of the influence of the surrounding sea points. The warm bias is greater in 22 colder winters, probably due to a stronger land-sea temperature contrast. The extreme 23 winters from the observations are also some of the most extreme winters in the 20CR 24 dataset (Figure 1); the original, non-detrended observed and 20CR ensemble-mean CET 25 values for these winters are given in Table 1.

\section{Mean Sea Level Pressure}

27 Figure 2 shows MSLP anomalies for a sample of the extreme winters. All extreme winters 28 except 1890 (discussed further below) show negative anomalies south and west of the UK, 29 along with positive anomalies to the north, exemplified by 1878 (Figure 2a) 1916 (Figure 30 2c) and 1939 (Figure 2d). These conditions recall the negative NAO, as they suggest a 
1 weakened Icelandic low and Azores high. This would result in a more southerly trans-

2 Atlantic jet and cold and dry conditions in the UK. This relationship between negative

3 NAO and cold UK winters has been widely accepted (Hurrell et al., 2003). The similarity

4 in the MSLP patterns supports the hypothesis that while many factors may cause extreme

5 winters, the effect of those factors is almost always communicated through a negative

6 NAO.

7 A contingency table for DJF means of the observed NAO and CET indices demonstrates 8 this relationship further (Table 2). These were constructed by sorting each index from low 9 to high, dividing the resulting array into six equal sections, then assigning each DJF to a 10 CET and NAO division. In each cell $(i, j)$, we show the number of winters observed $\left(O_{i, j}\right)$, 11 as well as the number that would be expected $\left(E_{i, j}\right)$ if the CET and NAO were unrelated, 12 given by

$E_{i, j}=\frac{\mathbf{\Sigma}_{m-1}^{E} O_{t, m} \mathbf{\Sigma}_{n-1}^{r} O_{n, j}}{N}$

14 where $c$ is the number of columns (6), $r$ is the number of rows (6) and $N$ is the number of 15 winters (139). The much larger $O_{i, j}$ values compared to $E_{i, j}$ in the upper-left (lower-right) 16 corners demonstrate a strong association between extremely negative (positive) NAO and 17 very cold (warm winters). We performed a $\chi^{2}$ test on the table for statistical significance, 18 where

$X^{2}=\sum_{i=1}^{r} \sum_{j=1}^{e} \frac{\left(O_{i, j}-E_{i, j}\right)^{2}}{E_{i, j}}$

20 For Table 2, $\chi^{2}=104.39$, which indicates that we can reject the null hypothesis that the 21 NAO and CET are unrelated at $99.5 \%$ confidence. A similar table was computed using all 2256 20CR ensemble members (not shown); it shows a similar pattern, but overestimates the 23 proportion of the coldest winters associated with the most negative NAO values.

24 This analysis supports the idea that the extreme winters occur during an extremely negative 25 phase of the NAO. However, this is not the case for all years, as the pressure anomalies do 26 not project perfectly onto the NAO structure. The influence of the AO can be seen in 1939 27 (Figure 2d), 1962 and December 2010 (Figure 2f). In addition, a south east shift in the 28 anomalous pressure centres, shown by 1878 (Figure 2a), suggest the influence of the EA. 
1 Interestingly, the winter of 1890/91 (Figure 2b) does not show a dipole of pressure

2 anomalies, only a large anomalously positive MSLP over the UK. This pattern is shown

3 more intensely by the December 1890 MSLP anomalies (Figure 2e), which suggests

4 neutral NAO conditions with a large blocking anticyclone over and northeast of the UK,

5 bringing colder air from continental Europe, in marked contrast to the negative AO/NAO

6 pattern in December 2010. Further meteorological parameters are analysed to understand

7 these results.

\section{Sea Surface Temperatures}

9 Global and North Atlantic sea surface temperature (SST) anomalies for all extreme winters

10 demonstrate no consistent pattern (not shown). In contrast to the case study of 2010 in

11 Maidens (2013), most extreme winters show only weak SST anomalies that vary in sign

12 and magnitude between one extreme winter and the next.

13 Notable features are moderate positive SST anomalies in the equatorial Pacific in 1939, 14 suggesting El Niño conditions (Figure 3b). In contrast, large negative SST anomalies off 15 the coast of South America are found in 1916 (Figure 3a) and December 2010 (not shown), 16 representing a strong La Niña. Pozo-Vazquez (2001) found a general association between 17 La Niña and a positive phase of the NAO. The MSLP anomalies for the La Nina events in 181916 and December 2010 do not support this, however, as these winters were clearly 19 negative NAO phases (Figure 2). The remaining extreme winters show no strong SST 20 anomalies in the ENSO region.

\section{Winds}

22 Anomalous winds at $850 \mathrm{hPa}$ (Figure 4), $500 \mathrm{hPa}$ and $250 \mathrm{hPa}$ (not shown) for all extreme 23 winters show anomalous easterlies over the UK, indicating an absence of the 24 climatological south-westerly winds across the UK. All winters except 1890 have wind 25 fields that resemble a classic negative NAO, with a more southerly jet into continental 26 Europe, exemplified by 1878 (Figure 4a), 1916 (Figure 4c) and 1939 (Figure 4d). In 1890 27 (Figure 4b), the anomalous easterlies are instead associated with a large anti-cyclone over 28 the North Sea, with anomalous westerlies over Scandinavia and easterlies across the 29 continent. Regardless of the cause, all extreme winters are associated with reduced 30 southwesterlies, which in some cases are replaced by mean easterlies or northeasterlies. 
1 Figure 5a shows statistically significant (at the 5\% level) positive 21 -year windowed 2 correlations between the ensemble-mean 20CR SWI and 20CR CET for each month in 3 DJF, indicating that strong south westerly winds are associated with warmer temperatures 4 in the UK. We note that there are periods of relatively weaker circulation-temperature 5 relationships, particularly for January in 1900-1910 and for December in 1945-1965.

6 Explaining these weaker correlations is outside the scope of this short study, but is clearly 7 worth further research. The 20CR NAO also shows significant 21-year windowed 8 correlations with the SWI (Figure 5b), suggesting that stronger south-westerly winds are 9 found during the positive NAO. This agrees with the observed enhanced meridional 10 pressure gradient across the North Atlantic that creates a stronger south-westerly jet. The 11 CET-NAO correlation is more stable over time than for CET-SWI. A contingency table 12 further demonstrates the overall strong relationship between the 20CR ensemble-member 13 SWI and the CET (Table 3). A $\chi^{2}$ test on this table indicates we can reject the null 14 hypothesis that the 20CR SWI and CET are unrelated at the $99.9 \%$ confidence level $15\left(\chi^{2}=3386.9\right)$. A table for the 20CR ensemble-member SWI and NAO was also statistically 16 significant at the $99.9 \%$ confidence level.

\section{Vertical Velocity}

18 Analysis of vertical velocity anomalies at $700 \mathrm{hPa}$ and $500 \mathrm{hPa}$ diagnostics of convective 19 activity in the extra-tropics and tropics, respectively, was inconclusive. The only consistent 20 pattern found was anomalous ascent over the Maritime Continent and West Pacific (not 21 shown). It is not clear how this affects the circulation anomalies over the Atlantic; further 22 investigation would be necessary to determine a physical mechanism.

\section{Specific Humidity}

24 Specific humidity anomalies found drier conditions surrounding the UK at $850 \mathrm{hPa}$ for all 25 extreme winters (not shown). These can be linked to the absence of south westerly winds 26 as well as the anomalous easterlies that bring dry continental air to the UK. Anomalously 27 moist conditions were seen in the Mediterranean, which can be explained by the 28 anomalously displaced southerly jet bringing moisture from the Atlantic. 


\section{Discussion and Conclusions}

2

This project examined common large-scale atmospheric circulation patterns during the seven most extremely cold UK winters in 1871-2010 using the 20CR. Prior to the introduction of the $20 \mathrm{CR}$, it was not possible to analyse most of these winters because "traditional" reanalysis datasets rely on upper-air data and so extend to only the midtwentieth century.

No single large-scale Northern Hemisphere atmospheric circulation pattern was associated with all seven extreme winters. The weakening of the climatological south-westerly winds over the UK, and in some cases the appearance of mean easterlies or north-easterlies, was found to be the dominant factor, but the change in the wind patterns had several causes. In all winters except 1890, the circulation resembled a negative NAO with varying degrees of contribution from the EA pattern. In 1890 however, a strong blocking anti-cyclone over the UK produced a similar effect on the wind patterns. To begin to understand and predict such extreme winters it is important to analyse the predictability of the direction and strength of the winds immediately upstream of the UK, as well as the predictability of the MSLP patterns that drive those wind patterns.

The analysis of the extreme winters, along with the NAO/CET contingency table (Table 2), supports the idea that most cold winters occur during negative NAO phases (Scaife et al,. 2008). Not all extremely negative NAO conditions led to extremely cold winters, however; Table 2 also showed that some milder winters occurred during highly negative NAO phases. There are similar outliers in the SWI/CET contingency table (Table 3), in which mild winters were associated with a lack of southwesterly winds. Further investigation is needed to understand why the association between the SWI and the CET sometimes breaks down. Figure 5a demonstrates that there have been particular decades, such as the 1960s, in which the SWI and CET display weaker 21-year windowed correlations for an individual month. With 56 ensemble members, the $20 \mathrm{CR}$ potentially provides a large sample of winters for future studies to investigate why the SWI and the CET became somewhat decoupled. While the ensemble members are not entirely independent, there is considerable intra-ensemble variability in the SWI, particularly early in the dataset, but little variability in CET (not shown). These periods of weaker SWI-CET correlations are an interesting and significant result, but understanding why this occurs is beyond the scope of this study. 
1 SSTs, vertical velocities and specific humidity anomalies demonstrated no conclusive 2 relationship with extreme cold winters. This analysis found no strong evidence that ENSO 3 events influenced any examined periods. This result is significant as the broad statistical 4 relationship between ENSO and UK temperature variability found by Pozo-Vazquez et al. 5 (2001) was not reproduced through this case-study analysis. However this signal may have 6 been masked by the reversal of the ENSO teleconnection from early to late winter, as 7 found by Moron and Gouirand (2003).

8 Although noted as the coldest Decembers on record, few similarities were found between 9 the Decembers of 1890 and 2010. The latter was associated with an intense negative NAO 10 during a La Niña. In contrast, December 1890 showed no significant NAO or ENSO 11 signal; instead anti-cyclonic blocking and easterly winds were found. This demonstrates 12 that, although the NAO has been seen to be the most common feature throughout the 13 examined winters, the most extreme conditions can occur in any favourable pressure 14 pattern, so long as there is an absence of south-westerly winds.

15 Further analysis is required to investigate the alternative possible pressure patterns such as 16 the EA and the AO in more depth. This would lead to a better understanding of their 17 influence on south-westerly jets. Similar to the NAO analysis undertaken here, an index for 18 both circulations could be created to determine any relationship with extremely cold 19 winters. However none of the NAO, EA or AO explained the MSLP anomalies found 20 during the winter of 1890. Analysis of additional extreme cold winters is also required to 21 ascertain the influence of blocking events.

22 In addition, identifying common features in atmospheric conditions of the autumns prior to 23 the extreme cold winters could prove to be essential for the predictability of cold winters. It 24 has been shown that autumn snow cover in Eurasia (Cohen and Jones, 2011) as well as 25 Arctic Sea Ice extent (Yang and Christensen, 2012) influence the NAO/AO and could 26 therefore be drivers of European winter variability. If a relationship were found between 27 autumn and winter conditions, it could improve the development and evaluation of 28 dynamical and statistical seasonal forecast systems.

29 It is possible that the atmospheric circulation anomalies shown were diluted by analysing 30 the DJF mean rather than the monthly means for extremely cold months. The magnitude of 31 the anomalies for December 1890 and 2010 were much greater than the DJF three-month 
1 averages. To better understand the factors that contribute to extreme events it would be

2 beneficial to examine the atmospheric conditions during only the extreme months.

3 This study has provided the first analysis of the atmospheric circulation patterns associated

4 with some of the most extremely cold winters in the UK in the past 140 years. In doing so, 5 the 20CR has been shown to provide dependable, realistic representations of past 6 atmospheric conditions over the North Atlantic region into the late $19^{\text {th }}$ century. It is 7 suggested that future studies of UK winter climate use the $20 \mathrm{CR}$ to provide the longest 8 possible estimate of past atmospheric conditions.

\section{Acknowledgements}

Dr. Nicholas Klingaman was supported by the National Centre for Atmospheric Science-

12 Climate, a Natural Environment Research Council collaborative centre. Support for the 13 Twentieth Century Reanalysis Project dataset is provided by the U.S. Department of 14 Energy, Office of Science Innovative and Novel Computational Impact on Theory and 15 Experiment program, and Office of Biological and Environmental Research, and by the 16 National Oceanic and Atmospheric Administration Climate Program Office. The authors 17 express their thanks to Dr. Gil Compo for providing timely 20CR data for 2010.

\section{References}

Baldwin MP, Dunkerton TJ. 2001. Stratospheric harbingers of anomalous weather regimes. Science, 294: 581-584.

Barnston AG, Livezey RE. 1986. Classification, Seasonality and Persistance of Low-Frequency Atmospheric Circulation Patterns. Mon. Weather Rev., 115: 1083-1126.

Brönnimann S, Xoplaki E, Casty C et al. 2007. ENSO influence on Europe during the last centuries. Climate Dyn., 28: 181-197.

Cohen J, Jones J. 2011. A new index for more accurate winter predictions. Geophys. Res. Lett., 38 : L21701.

Compo GP and Coauthors. 2011. The Twentieth Century Reanalysis Project. Q.J.Roy. Meteor. Soc., 137: 1-28.

Deser D. 2000. On the Teleconnectivity of the "Arctic Oscillation". Geophys. Res. Lett., 27: 779782.

Ebdon RA. 1975. The quasi-biennial oscillation and its association with tropospheric circulation patterns, Met. Mag., 104: 282-297. 
Evensen G. 2003. The Ensemble Kalman Filter: theoretical formulation and practical

2 implementation. Ocean Dynam., 53, 343-367.

3 Frehlich R, Sharman R. 2008. The use of structure functions and spectra from numerical model 4 output to determine effective model resolution. Monthly Weather Review, 136, 1537-1553.

5 George DG, Jarvinen M, Arvola L. 2004. The influence of the North Atlantic Oscillation on the

6 winter characteristics of Windermere (UK) and Paajarvi (Finland). Boreal Environ. Res., 9: 389-

7399.

8 Hirschi J J-M, Sinha B. 2007. Negative NAO and cold Eurasian winters: How exceptional was the

9 winter of 1962/1963?. Weather. 62: 43-48.

10 Hurrell JW. 2003. An overview of the North Atlantic Oscillation. The North Atlantic Oscillation:

11 Climatic Significance and Environmental Impact, Geophys. Monogr., 134: American Geophysical

12 Union, Washington, DC, 7-12.

13 Ineson S, Scaife AA. 2009. The role of the stratosphere in the European climate response to El Niño.

$14 \quad$ Nature Geoscience, 2: 32 - 36.

Lockwood M, Harrison RG, Owens MJ et al. 2011. The solar influence on the probability of

17 relatively cold UK winters in the future. Environ. Res. Lett., 6: 11pp.

18 Maidens A, Arribas A, Scaife AA et al. 2013. The Influence of Surface Forcings on Prediction of the

19 North Atlantic Oscillation Regime of Winter 2010/11. Mon. Wea. Rev., 141: 3801-3813.

20 Moore GWK, Renfrew IA. 2012. Cold European winters: interplay between the NAO and the East

21 Atlantic mode. Atmosph. Sci. Lett., 13: 1-8.

Moron V, Gouirand I. 2003. Seasonal modulation of the ENSO relationships with sea level pressure anomalies over the North Atlantic in October-March 1873-1996. Int. J. Climatol., 23: 143-155.

Parker DE, Legg TP, Folland CK. 1992. A new daily Central England Temperature Series, 17721991.Intern. J. Climate, 12: 317-342.

Pozo-Vazquez D, Esteban-Parra MJ, Rodrigo FS et al. 2001. The Association between ENSO and

28 Winter Atmospheric Circulation and Temperature in the North Atlantic Region. J. Climate, 14:

$29 \quad 3408-3420$.

30 Rayner NA, Parker DE, Horton EB et al. 2003. Global analyses of sea surface temperature, sea ice, and

31 night marine air temperature since the late nineteenth century. Geophys. Res. Lett., 108: 4407.

32

Rodwell M.J, Rowell DP, Folland CK. 1999. Oceanic forcing of the wintertime North Atlantic Oscillation and European climate. Nature, 398: 320-323.

Scaife AA, Folland CK, Alexander LV et al. 2008. European Climate Extremes and the North 37 Atlantic Oscillation. J. Climate, 21: 72-83.

38 Thompson DWJ, Wallace JM. 2001. Regional climate impacts of the Northern Hemisphere 39 annular mode. Science, 293: 85-89.

40 Wang L, Chen W. 2010. Downward Arctic Oscillation signal associated with moderate weak 41 stratospheric polar vortex and the cold December 2009. Geophys. Res. Lett., 37: L09707.

42 Yang, S., Christensen, JH. 2012. Arctic sea ice reduction and European cold winters in CMIP5 43 climate change experiments. Geophys. Res. Lett., 39: L20707. 


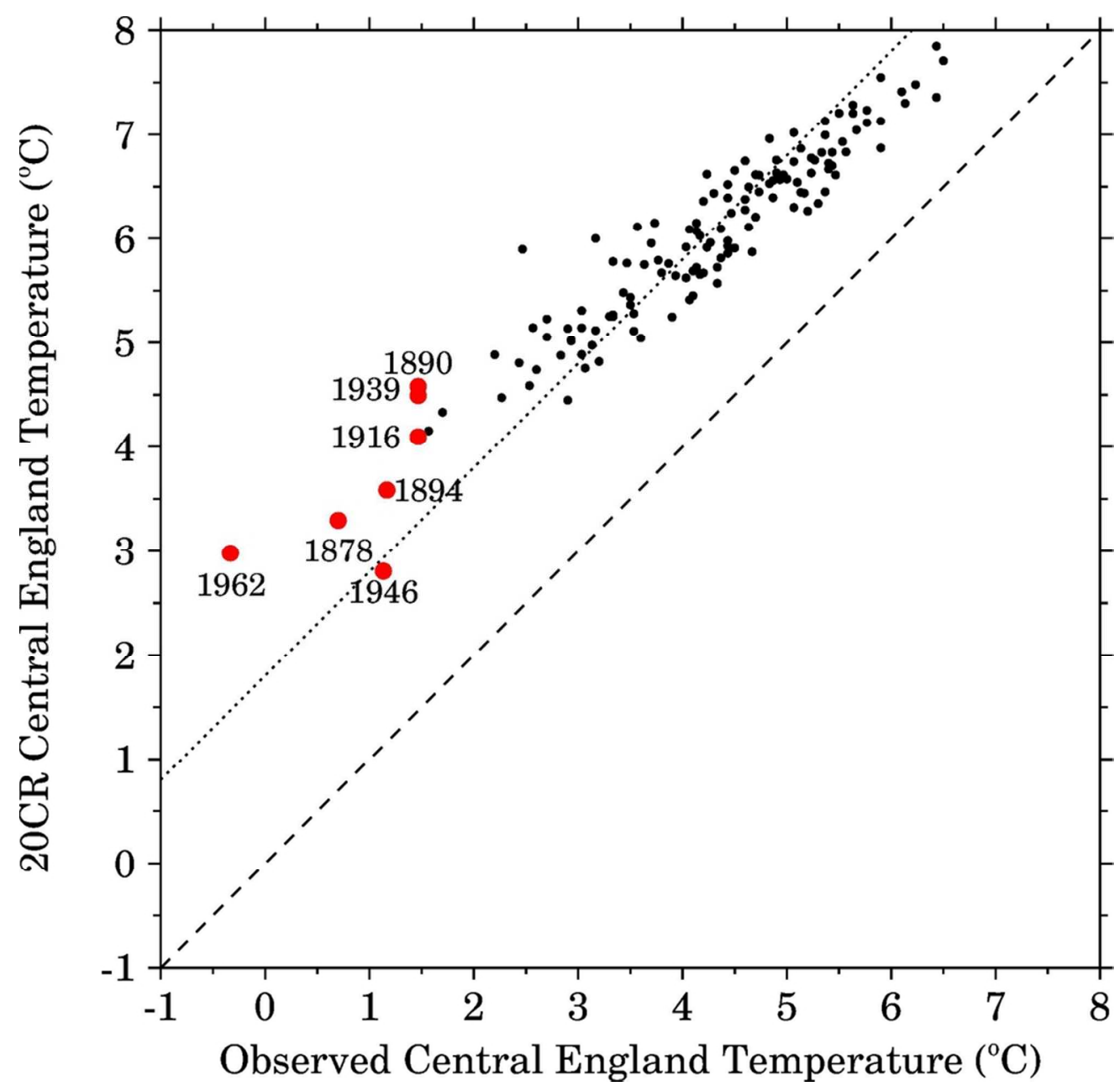

Figure 1: Scatter plot showing the ensemble mean 20CR CET $\left({ }^{\circ} \mathrm{C}\right)$ against the observed CET $\left({ }^{\circ} \mathrm{C}\right)$ for each winter between 1871-2009. Winters examined in this study are labelled and highlighted in red. The dashed line represents a perfect correspondence between observed and 20CR ensemble-mean CET, if the 20CR had zero mean bias. The dotted line represents a perfect correspondence, taking into account the $20 \mathrm{CR}$ ensemble-mean mean bias of $+1.8 \mathrm{C}$. $82 \times 80 \mathrm{~mm}(300 \times 300 \mathrm{DPI})$ 
a. DJF 1878

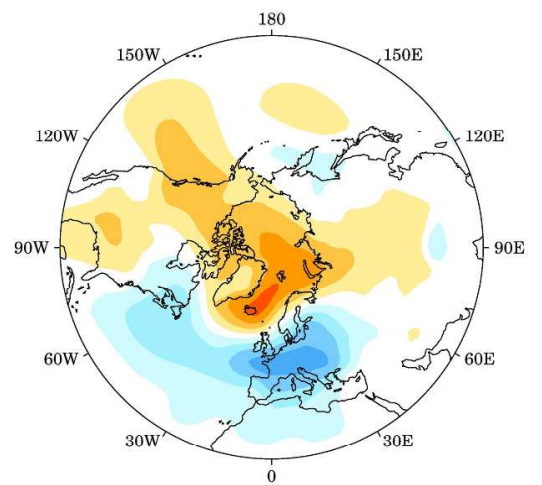

c. DJF 1916

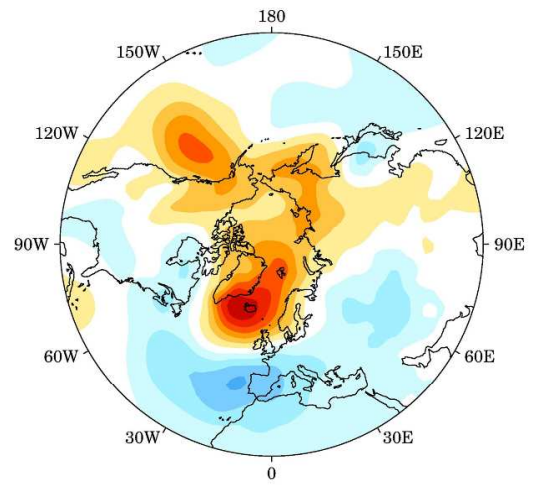

e. December 1890

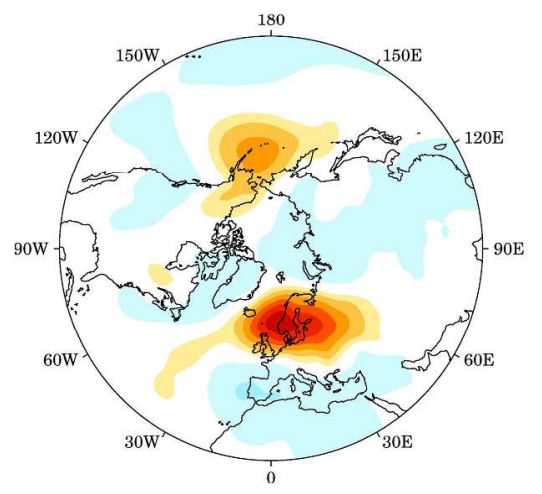

b. DJF 1890

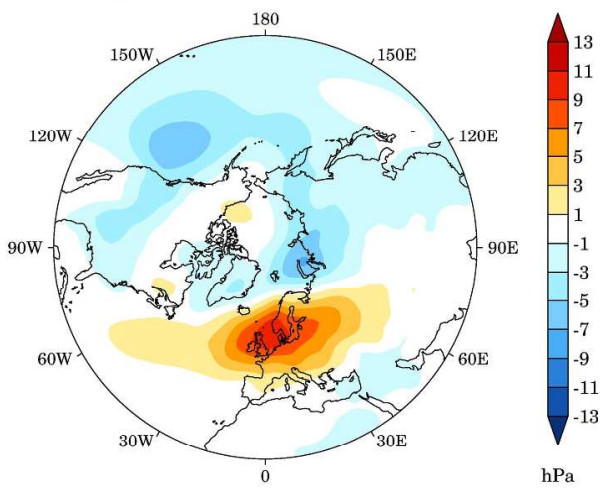

d. DJF 1939

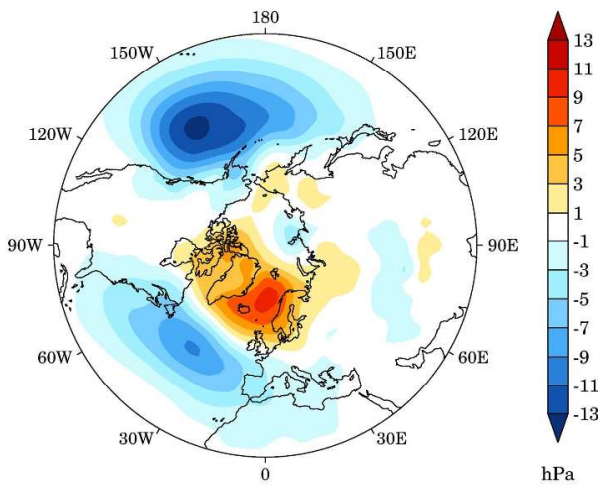

f. December 2010

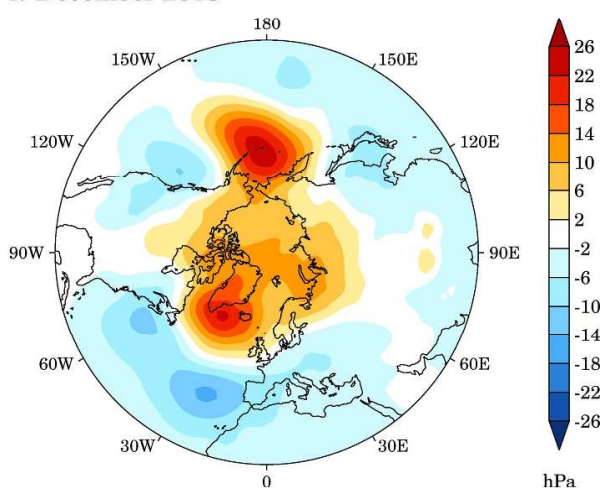

Figure 2: MSLP anomalies (hPa) for DJF a) 1878, b) 1890, c) 1916, d) 1939 and December e) 1890 and f) 2010. Anomalies are computed from the 30-year running mean, except for DJF 1878 and December 2010, for which we use the means of 1871-1900 and 1981-2010, respectively.

$225 \times 309 \mathrm{~mm}(300 \times 300 \mathrm{DPI})$ 


\section{Page 15 of 20}

a. DJF 1916

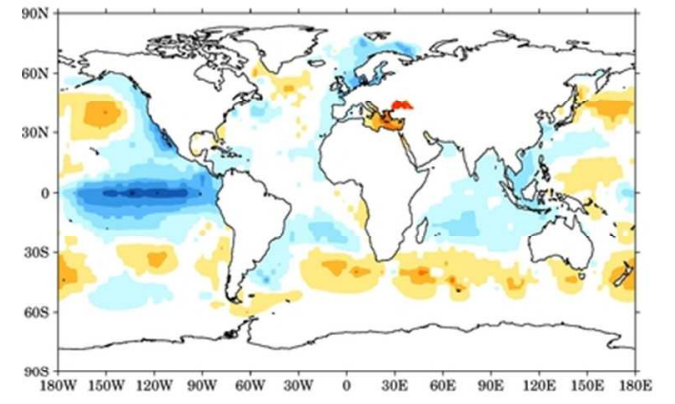

b. DJF 1939

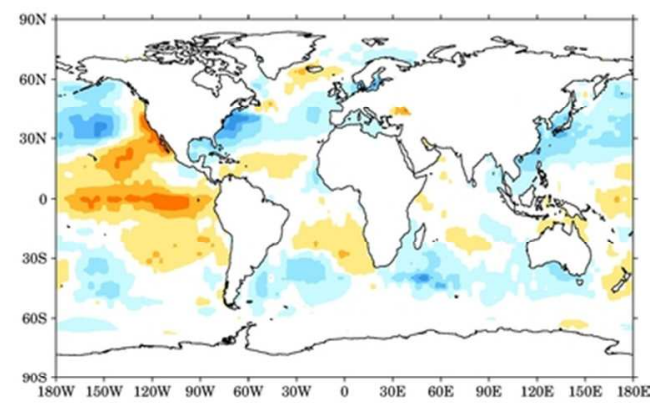

Figure 3: Sea Surface Temperature Anomalies $\left({ }^{\circ} \mathrm{C}\right)$ with respect to the 30 -year running mean for DJF a) 1916 and b) 1939.

$71 \times 29 \mathrm{~mm}(300 \times 300$ DPI $)$ 


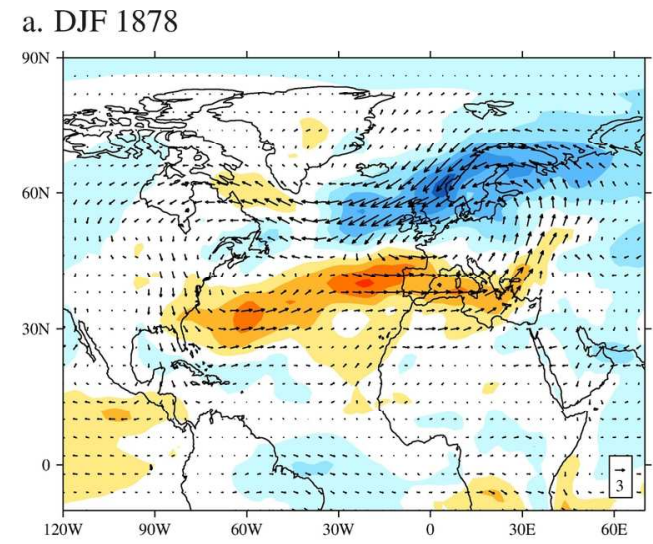

b. DJF 1890

c. DJF 1916
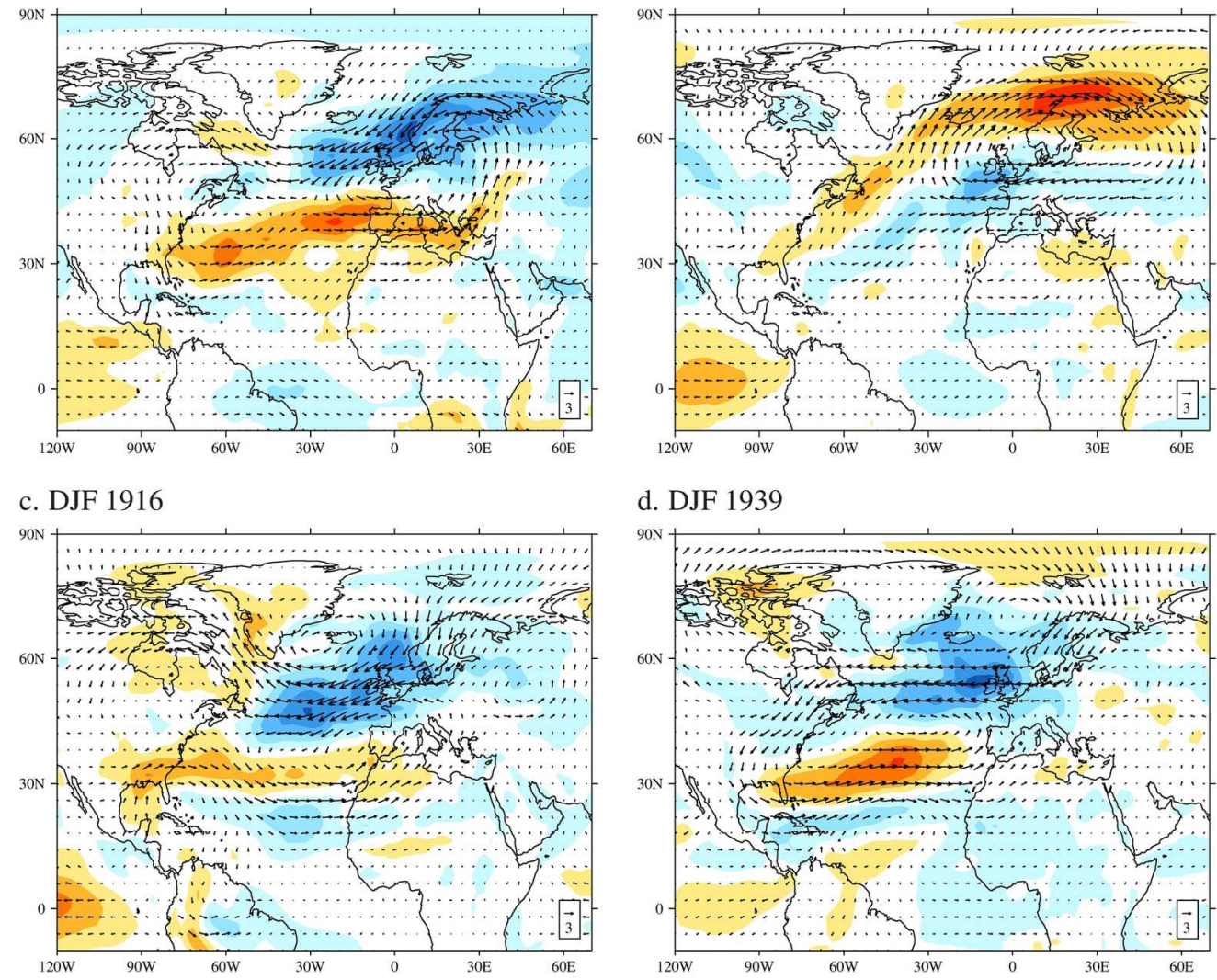

d. DJF 1939

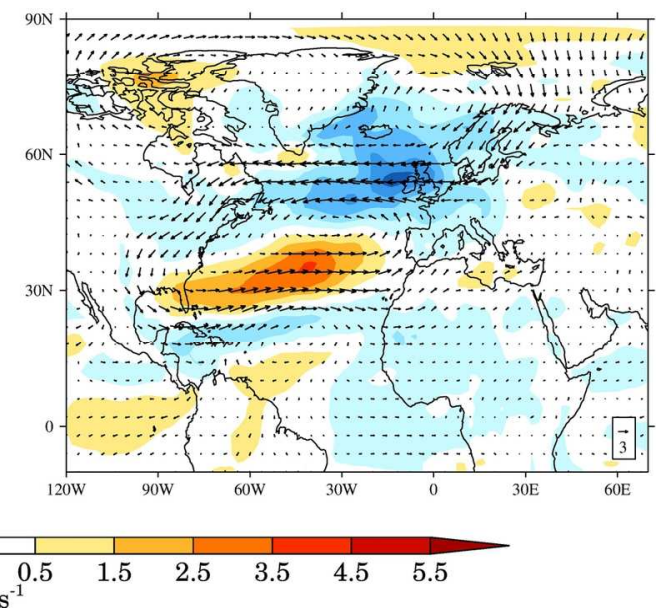

Figure 4: Vectors show anomalous $850 \mathrm{hPa}$ winds (reference magnitude $3 \mathrm{~m} \mathrm{~s}-1$ ) and shading shows anomalous $850 \mathrm{hPa}$ wind speed (m s-1) during DJF a) 1878, b) 1890, c) 1916 and d) 1939. Anomalies were computed as for MSLP in Figure 2. $159 \times 146 \mathrm{~mm}(300 \times 300$ DPI $)$ 
a. 20CR CET and SWI

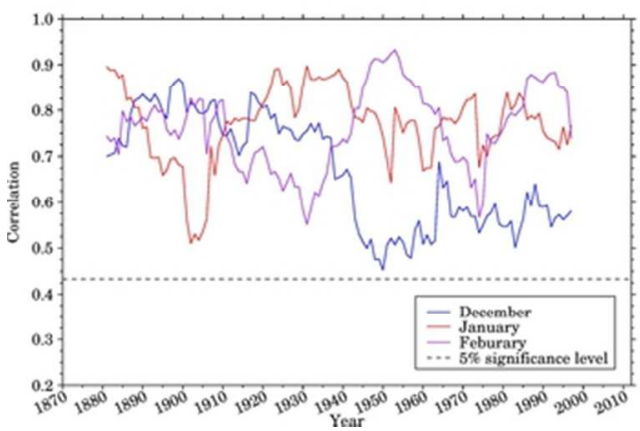

b. 20CR NAO and SWI

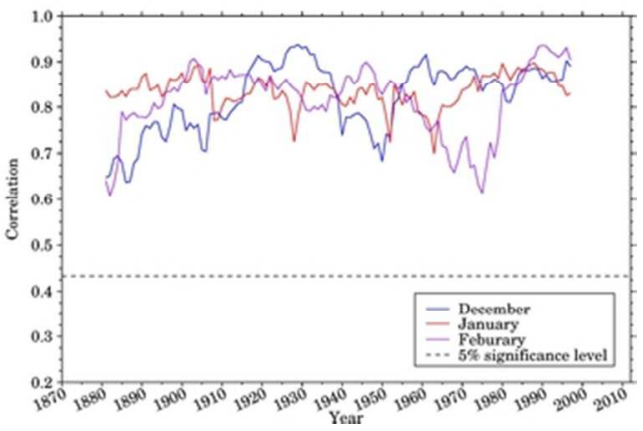

Figure 5: 21-year-windowed correlation between the monthly-mean, ensemble-mean 20CR SWI and a) 20CR CET and b) 20CR NAO for each winter month from 1871 to 2009 . The dashed line indicates the $5 \%$ significance level. The year on the horizontal axis refers to the central year of the 21-year window. $60 \times 21 \mathrm{~mm}(300 \times 300 \mathrm{DPI})$ 
Table 1: Summary table showing the non-detrended, observed and 20CR values for CET and NAO as well as the ensemble-mean 20CR SWI for the identified extreme winters and for Decembers 1890 and 2010. The year for the winters refers to the year in December.

\begin{tabular}{|c|c|c|c|c|c|}
\hline & $\begin{array}{c}\text { Observed } \\
\text { CET } \\
{ }^{\circ} \boldsymbol{C}\end{array}$ & $\begin{array}{c}\text { 20CR CET } \\
{ }^{\circ} \boldsymbol{C}\end{array}$ & $\begin{array}{c}\text { NAO Index } \\
\text { Observed } \\
\boldsymbol{h P a}\end{array}$ & $\begin{array}{c}\text { NAO Index } \\
\mathbf{2 0 C R} \\
\boldsymbol{h P a}\end{array}$ & $\begin{array}{c}\text { South } \\
\text { Westerly } \\
\text { Index } \boldsymbol{m s}^{-1}\end{array}$ \\
\hline Winter 1878 & 0.7 & 3.4 & -1.61 & -1.91 & -0.12 \\
\hline Winter 1890 & 1.5 & 4.4 & -0.43 & -0.4 & 3.52 \\
\hline Winter 1894 & 1.2 & 3.7 & -2.49 & -2.58 & -1.77 \\
\hline Winter 1916 & 1.5 & 4.2 & -2.71 & -2.57 & -0.91 \\
\hline Winter 1939 & 1.5 & 4.5 & -1.97 & -1.90 & 1.48 \\
\hline Winter 1946 & 1.1 & 3.7 & -1.55 & -1.77 & 1.28 \\
\hline Winter 1962 & -0.3 & 3.2 & -2.77 & -2.76 & 0.76 \\
\hline December 1890 & -0.8 & 2.65 & -3.05 & -2.78 & 0.83 \\
\hline December 2010 & -0.7 & 4.27 & -4.92 & -4.48 & 0.37 \\
\hline
\end{tabular}


Table 2: A contingency table for observed DJF-mean NAO and CET for 1871-2009. The bold values on the top line of each cell show the number of winters for each joint division of NAO and CET values. The italicized values on the bottom line show the number of winters that would be expected if the NAO and CET were unrelated; these values are used for the $\chi^{2}$ test reported in the text.

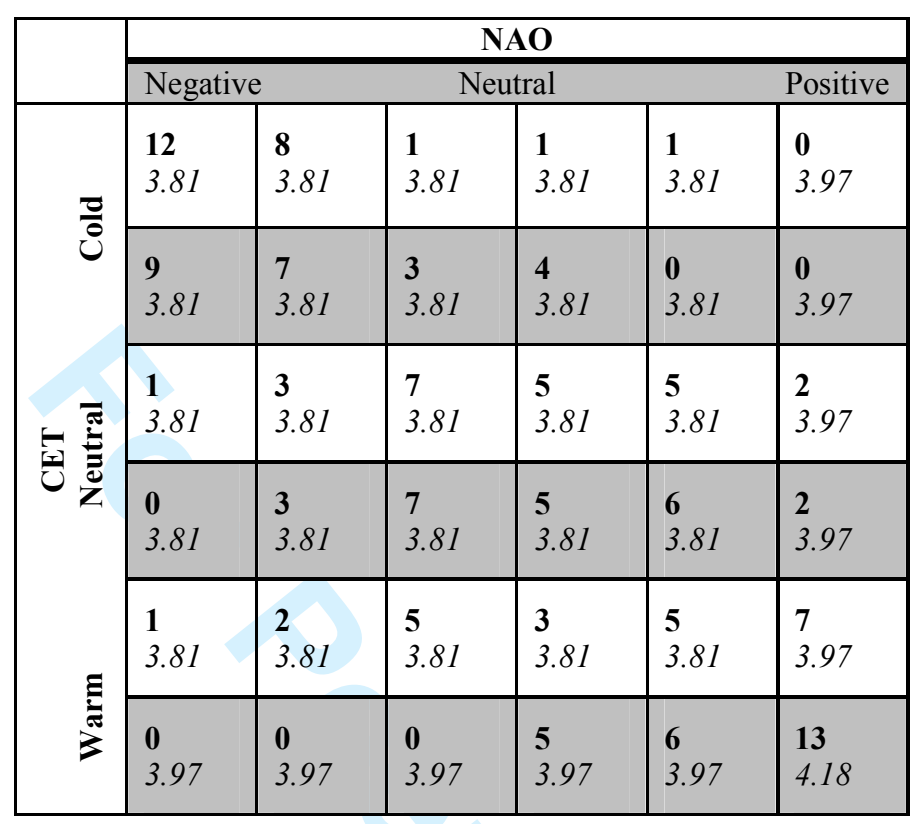


Table 3: As in Table 2, but for 20CR ensemble-member DJF-mean SWI and CET for 1871-2009.

\begin{tabular}{|c|c|c|c|c|c|c|}
\hline & \multicolumn{6}{|c|}{ SW Index } \\
\hline & \multicolumn{2}{|c|}{ Negative } & \multicolumn{2}{|c|}{ Neutral } & \multirow{3}{*}{$\begin{array}{l}\mathbf{5 6} \\
216.23\end{array}$} & Positive \\
\hline \multirow{4}{*}{ 흥 } & 546 & 367 & 211 & 112 & & \\
\hline & 216.23 & 216.23 & 216.23 & 216.23 & & 206.83 \\
\hline & 421 & 182 & 267 & 220 & 198 & 0 \\
\hline & & 210.23 & & 210.23 & 210.23 & 200.83 \\
\hline \multirow{4}{*}{ 四 } & 212 & 317 & 262 & 243 & 156 & 98 \\
\hline & & & & & & \\
\hline & & 249 & 332 & 216 & 267 & 157 \\
\hline & 216.23 & 216.23 & 216.23 & 216.23 & 216.23 & 206.83 \\
\hline \multirow{4}{*}{ 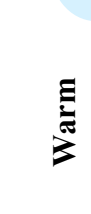 } & 46 & 173 & 120 & 168 & 335 & 446 \\
\hline & 216.23 & 216.23 & 216.23 & 216.23 & 216.23 & 206.83 \\
\hline & $\begin{array}{l}\mathbf{0} \\
206.83\end{array}$ & $\begin{array}{l}\mathbf{0} \\
206.83\end{array}$ & $\begin{array}{l}96 \\
206.83\end{array}$ & $\begin{array}{l}329 \\
206.83\end{array}$ & $\begin{array}{l}276 \\
206.83\end{array}$ & $\begin{array}{l}\mathbf{5 3 1} \\
197.84\end{array}$ \\
\hline & & & & & & \\
\hline
\end{tabular}

http://mc.manuscriptcentral.com/weather 